\title{
Evolution of Rolling Textures of Cold Rolled Copper Foils
}

\author{
Su-Hyeon Kim ${ }^{1}$, Seung Zeon Han ${ }^{1}$, Chang Joo Kim ${ }^{1}$, In-Youb Hwang ${ }^{2}$ and Fuxing Yin ${ }^{3}$ \\ ${ }^{1}$ Korea Institute of Materials Science, 531 Changwondaero, Changwon, Gyeongnam, 641-831, Korea \\ ${ }_{2}^{2}$ Poongsan Co., 611 Daejung-Ri, Onsan-Oup, Ulju-Kun, UIsan, 689-892, Korea \\ ${ }^{3}$ National Institute for Materials Science, Tsukuba 305-0047, Japan
}

\begin{abstract}
The texture evolution of cold rolled tough pitch copper foils could be changed by altering the initial texture and microstructure before cold rolling. The development of $\beta$-fiber texture was substantially suppressed even after $92 \%$ reduction for the case of abnormally coarse initial grain structure and extremely strong initial cube texture. Instead, the intensity of cube and RD (rolling direction)-rotated cube texture components was increased continuously by increasing the intensity of the initial cube texture. [doi:10.2320/matertrans.MRA2008330]
\end{abstract}

(Received September 11, 2008; Accepted December 1, 2008; Published January 21, 2009)

Keywords: copper foil, rolling, texture, cube texture, $\beta$-fiber, initial texture

\section{Introduction}

Rolled copper foils are often used as conductive metal layers in flexible printed circuit boards. Texture control is important in order to enhance flexibility or the bending endurance of rolled copper foils. Cube texture is the most favorable component of the flexibility of copper foils. ${ }^{1,2)}$ Heavily cold rolled coppers typically exhibit strong $\beta$-fiber texture, which frequently changes into the cube texture after recrystallization. ${ }^{3)}$ Anomalous texture evolutions of rolled copper foils have been reported; the foils possess very strong cube texture in the as-rolled state, which result in unique recrystallization textures in the annealed state. ${ }^{4,5)}$ The mechanism of texture evolution in cold rolled copper foils is not fully understood.

In the present research study, cold rolled copper foils with different thicknesses were prepared by changing the initial thickness before rolling. The evolutions of the textures and microstructures were investigated and the influence of initial texture and microstructure was discussed.

\section{Experimental}

The material used in this study is tough pitch copper (C11000), which contains oxygen as copper oxide particles. Table 1 indicates the chemical composition of the material measured by an ICP (inductively coupled plasma) method and an oxygen analysis.

Three kinds of samples with different thicknesses were prepared by a rolling schedule as shown in Fig. 1. Hot rolled strip with $9 \mathrm{~mm}$ thickness was cold rolled to different thicknesses, $1.55,1.05$, and $0.45 \mathrm{~mm}$, and then annealed to be recrystallized. TP450a was prepared by higher temperature annealing in order to intentionally increase the intensity of cube texture. TP1550a, TP1050a, and TP450a were cold rolled to 125,85 , and $36 \mu \mathrm{m}$ thicknesses, respectively. Thickness reduction by the final cold rolling is $92 \%$ regardless of thickness of the samples.

Macroscopic textures of the samples were measured by a back reflection X-ray diffraction method. Three incomplete pole figures (111), (200), and (220) were measured; and complete pole figures and orientation distribution functions
(ODFs) were calculated using Labotex software by arbitrarily defined cells (ADC) method. ${ }^{6)}$ The specimens were polished parallel to the rolling plane mechanically and chemically to expose the center layers to measure. The textures on a microscopic scale were measured by the techniques of scanning electron microscope-electron back-scattered diffraction (SEM-EBSD). EBSD samples were mechanically polished and subsequently electro-polished. Microstructures of the specimens were observed under an optical microscope and a transmission electron microscope.

\section{Results and Discussion}

Figure 2 shows the ODFs of TP1550a, TP1050a, and TP450a, which are cold rolled and annealed sheets with $1.55,1.05$, and $0.45 \mathrm{~mm}$ thicknesses, respectively. Strong cube textures developed but those intensities increased with decreasing thickness of the specimens. Because three samples were cold rolled from the same thickness, reduction increases with decreasing thickness of the samples. Higher cold rolling reduction could substantially enhance the development of cube texture in the specimen TP450a. Figure 3 shows the longitudinal section optical microstructures of each specimen. Recrystallized grain structures can be seen in all the specimens. Compared to TP1550a and TP1050a, TP450a exhibited an inhomogeneous grain size distribution, which can be characterized by the mixture of coarse grains and fine grains. In order to discriminate the orientations of these two kinds of grains, EBSD mapping in the longitudinal section was carried out and shown in Fig. 4. Solid lines in the micrograph indicate high angle boundaries with a misorientation of more than $15 \mathrm{deg}$, and grain thicknesses were measured by a linear intersection method. Coarse grains with thickness of larger than $15 \mu \mathrm{m}$ mainly possessed the cube orientation, but the fine grains had various orientations. Grain boundary misorientation histogram shows the presence of large amount of low angle boundaries, which indicates that cube-oriented grains are agglomerated and impinge on each other. Grain boundary misorientation histogram also shows the presence of twins of cube orientation, which were indexed by $\{122\}\langle 212\rangle$ in (111) pole figure. 
Table 1 Chemical composition of tough pitch copper.

\begin{tabular}{ccccccccccccc}
\hline & $\mathrm{Fe}$ & $\mathrm{Pb}$ & $\mathrm{S}$ & $\mathrm{Bi}$ & $\mathrm{As}$ & $\mathrm{Sb}$ & $\mathrm{O}$ & & $\mathrm{Cu}$ \\
\hline $\begin{array}{c}\text { Composition, } \\
(\text { mass\% })\end{array}$ & $<0.001$ & $<0.001$ & $<0.001$ & $<0.001$ & & $<0.001$ & $<0.001$ & 0.018 \\
\hline
\end{tabular}

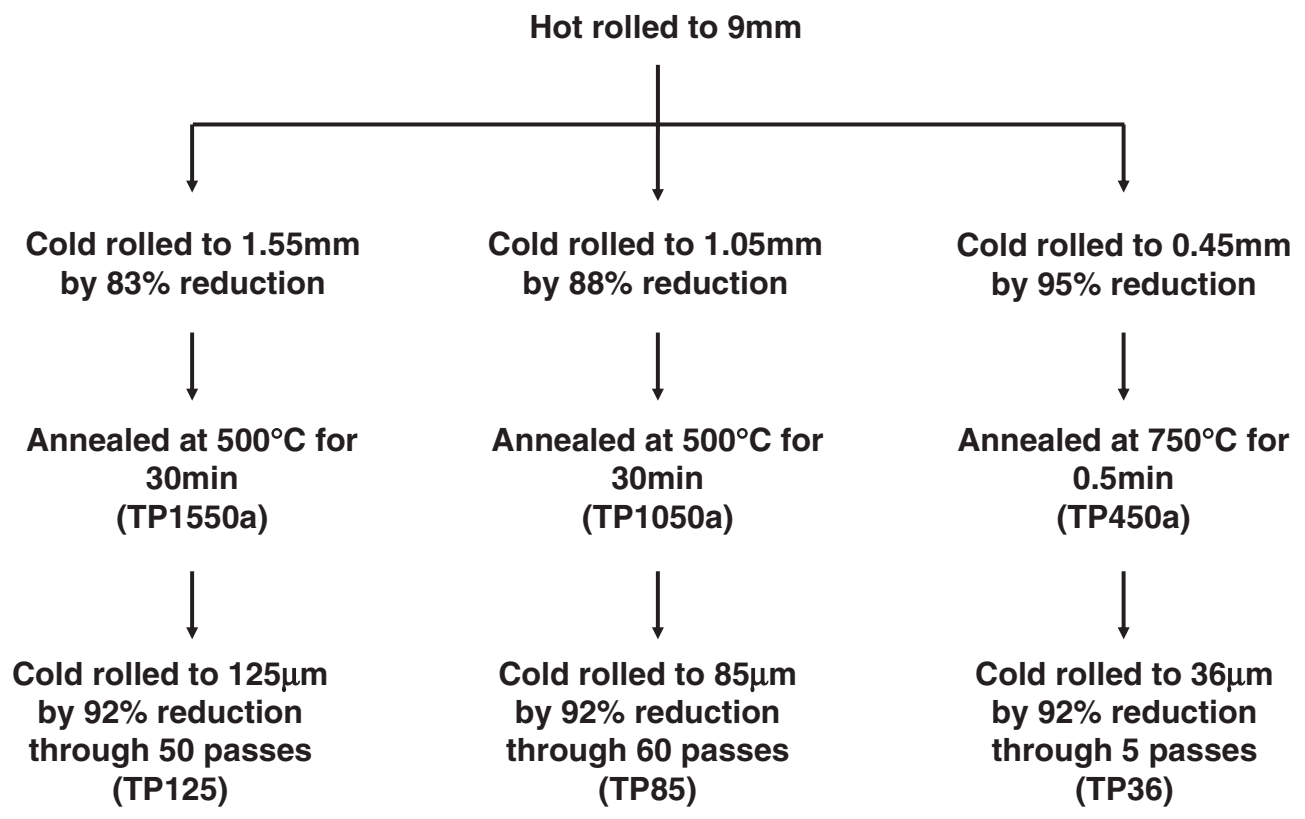

Fig. 1 Rolling schedule of tough pitch copper foils with three different thicknesses.

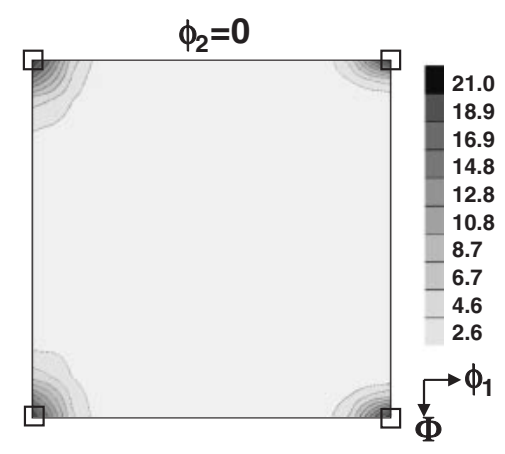

(a)

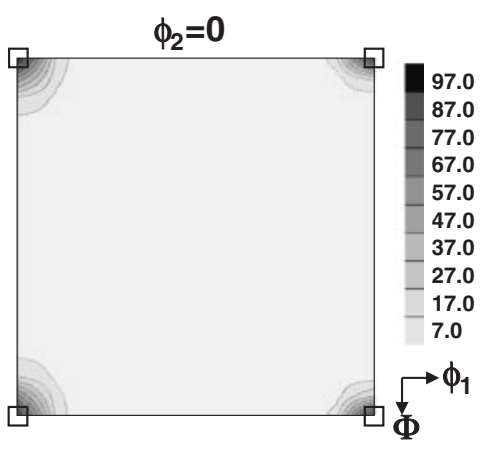

(b)

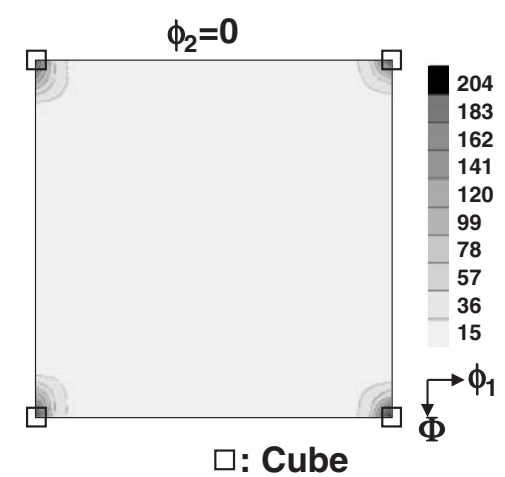

(c)

Fig. 2 ODFs in $\phi_{2}=0$ sections of (a) TP1550a (annealed $1.55 \mathrm{~mm}$ thick sample), (b) TP1050a (annealed $1.05 \mathrm{~mm}$ thick sample), and (c) TP450a (annealed $0.45 \mathrm{~mm}$ thick sample).

Figure 5, Figure 6, and Figure 7 show the texture evolutions of TP125 (125 $\mu \mathrm{m}$ thick sample), TP85 $(85 \mu \mathrm{m}$ thick sample), and TP36 (36 $\mu \mathrm{m}$ thick sample), respectively. TP125 sample exhibited a typical cold rolling texture characterized by $\beta$-fiber, running from the copper orientation $\{112\}\langle 111\rangle$, over the $S\{123\}\langle 634\rangle$, to the brass orientation $\{011\}\langle 211\rangle$ in the Euler orientation space. In the TP85 specimen, a new orientation defined as RD (rolling direction)-rotated cube, indexed by $\{025\}\langle 100\rangle$, was found in the $\phi_{2}=0$ section. In the TP36 specimen, cube $(\{001\}\langle 100\rangle)$ and RD-rotated cube textures developed significantly with reducing intensity of $\beta$-fiber texture. Figure 8 shows the orientation densities along the $\beta$-fiber, and those along the cube to goss $(\{011\}\langle 100\rangle)$ orientations. The texture components found in TP125, TP85, and TP36 specimens can be ordered from the maximum to the minimum as follows.

\section{TP125}

S $>$ copper $>$ brass $>$ RD-rotated cube $>$ cube TP85

$$
\begin{aligned}
& \mathrm{S}>\text { copper }>\text { RD-rotated cube }>\text { brass }>\text { cube } \\
& \text { TP36 } \\
& \text { RD-rotated cube }>\text { cube }>\mathrm{S}>\text { copper }>\text { brass }
\end{aligned}
$$

The main texture of the cold rolled foils was changed from the $\beta$-fiber to the cube or RD-rotated cube with decreasing thickness of the foils. 

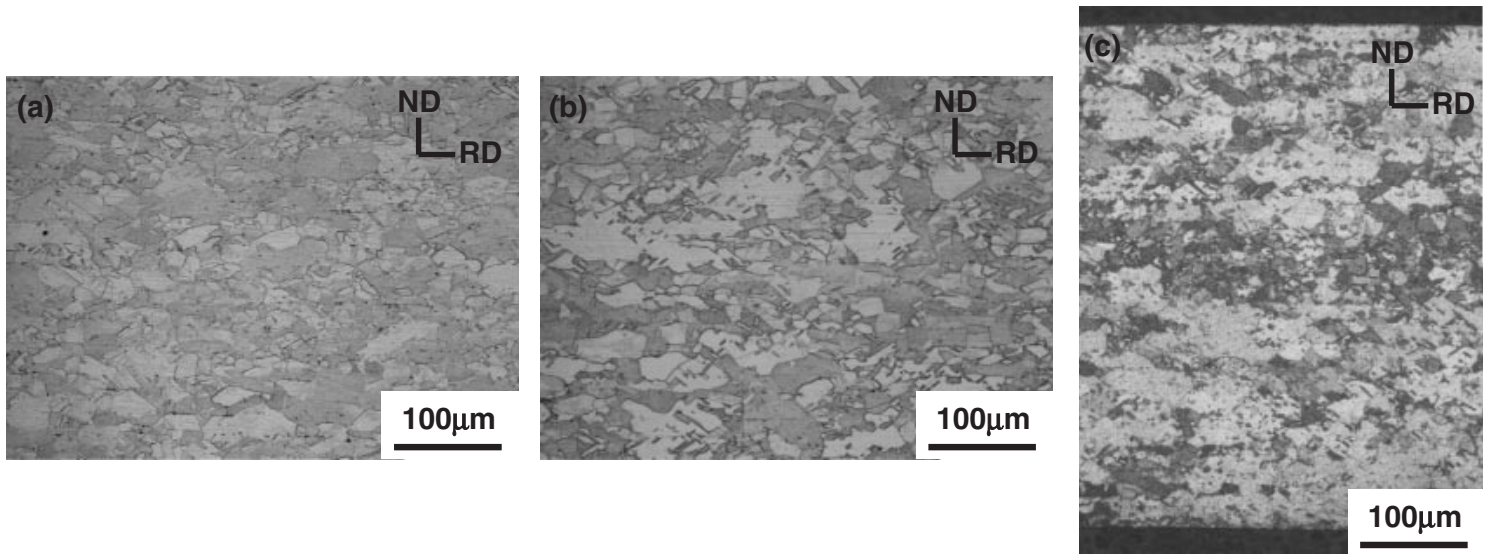

Fig. 3 Longitudinal section optical micrographs of (a) TP1550a (annealed $1.55 \mathrm{~mm}$ thick sample), (b) TP1050a (annealed $1.05 \mathrm{~mm}$ thick sample), and (c) TP450a (annealed $0.45 \mathrm{~mm}$ thick sample).

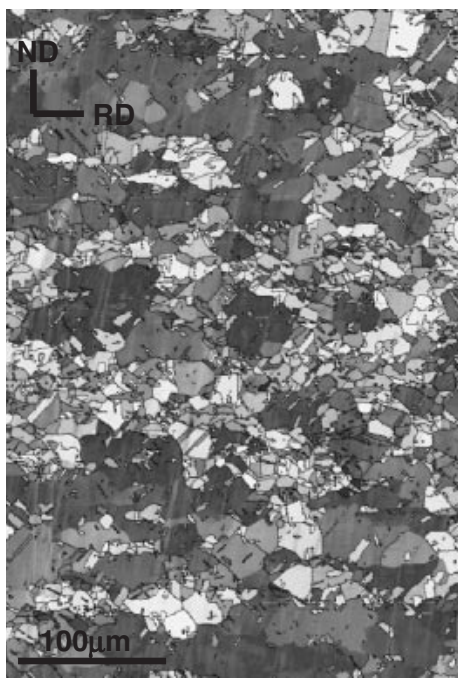

(a)

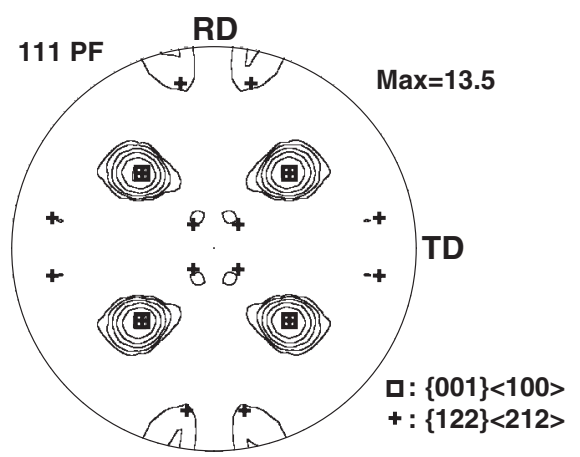

(c)

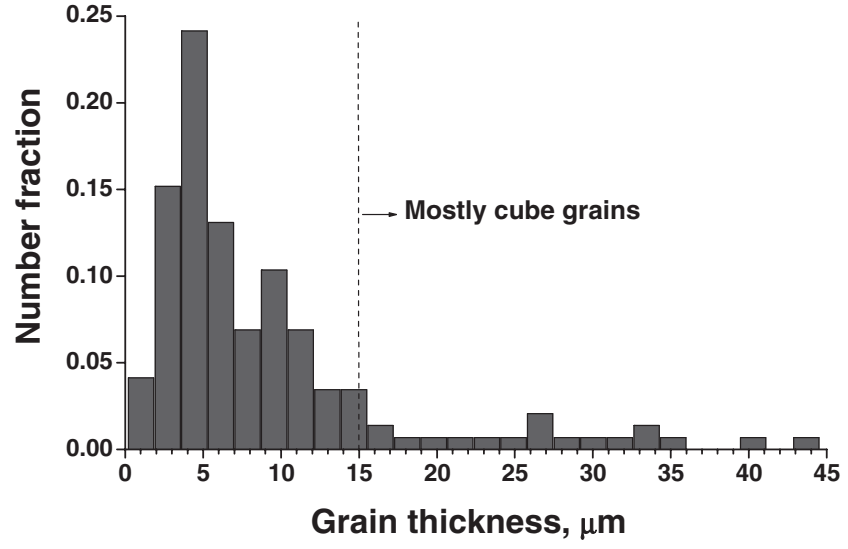

(b)

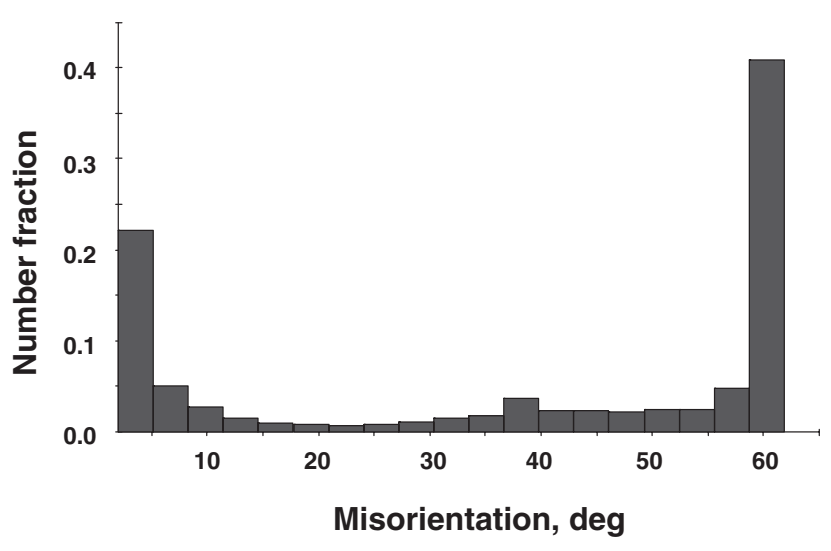

(d)

Fig. 4 (a) Longitudinal section orientation imaging microscopy, (b) grain thickness histogram, (c) (111) pole figure, and (d) grain boundary misorientation histogram of TP450a (annealed $0.45 \mathrm{~mm}$ thick sample).

Figure 9 shows the microstructures of cold rolled foils. Elongated grain structures indicate that the materials were heavily cold rolled. Compared to TP125 and TP85 specimens showing fine and homogeneous grain structures, the microstructure of TP36 was characterized by a mixture of fine and coarse grains. The origin of coarse grains in the deformed state would be coarse grains in the initial state before rolling. Inhomogeneous microstructure of TP450a could retain even after $92 \%$ deformation to form coarse grains in TP36. Microstructure evolution of TP36 was observed under TEM and shown in Fig. 10. Refined as well as less refined grains were present and the orientation measured at one of the coarse grains were close to $\{001\}\langle 100\rangle$.

The presence of coarse grains in the TP36 sample was also confirmed by the EBSD analysis. Figure 11(a) shows the pattern quality micrograph in the longitudinal section of 

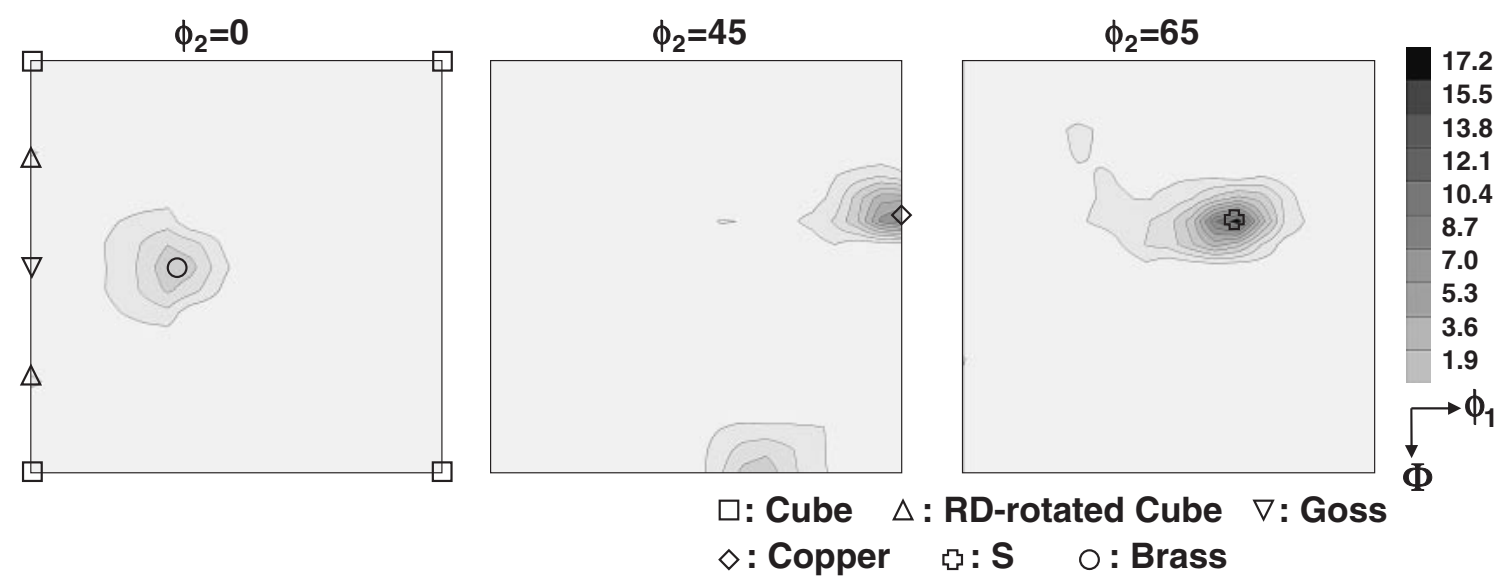

Fig. 5 ODFs in $\phi_{2}=0,45$, and 65 sections of TP125 (125 $\mu \mathrm{m}$ thick sample).
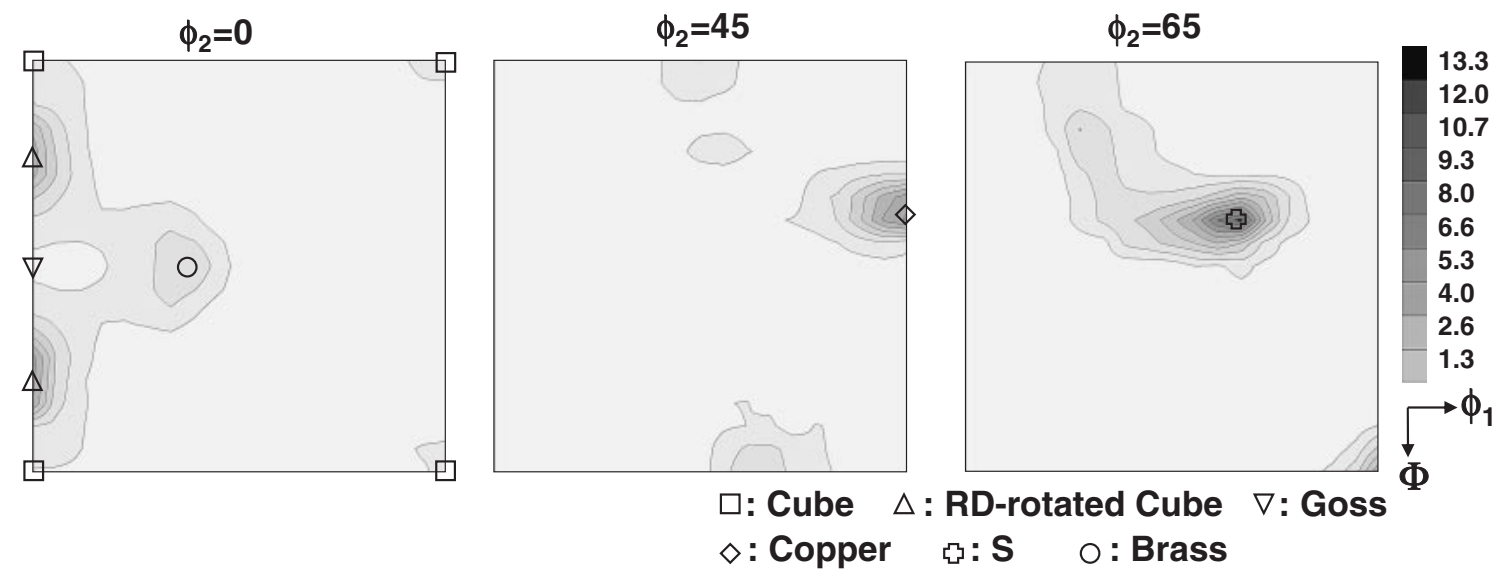

Fig. 6 ODFs in $\phi_{2}=0,45$, and 65 sections of TP85 ( $85 \mu \mathrm{m}$ thick sample).
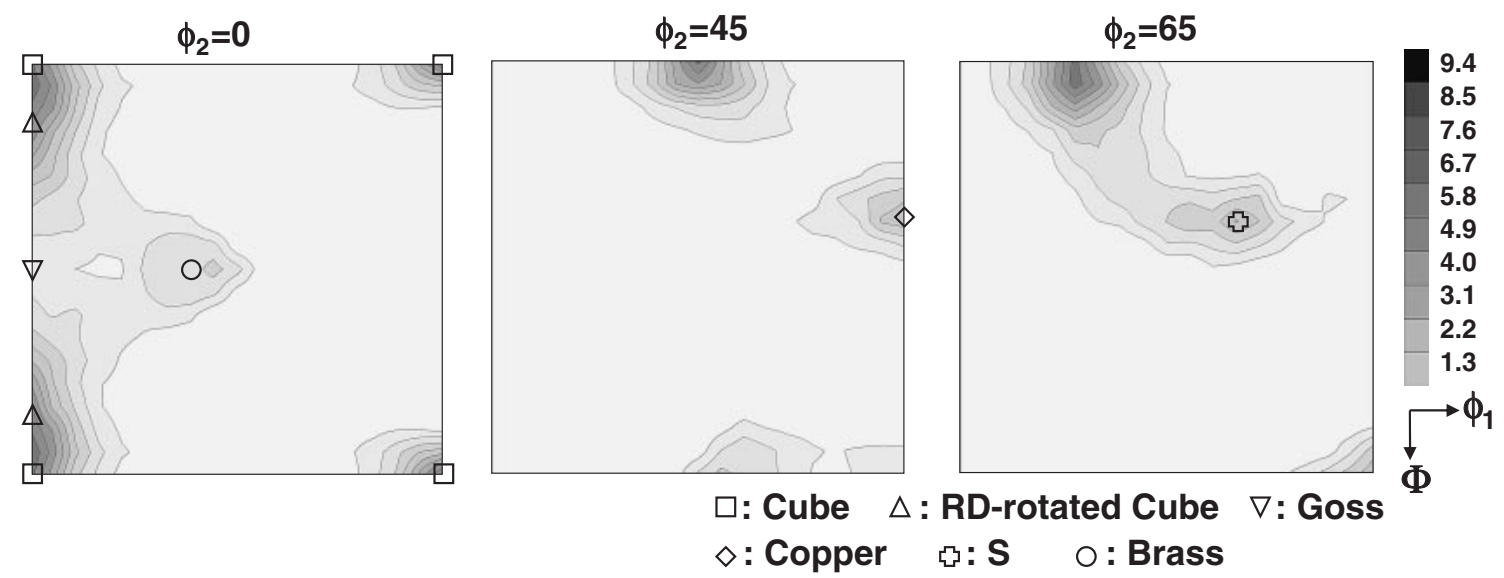

Fig. 7 ODFs in $\phi_{2}=0,45$, and 65 sections of TP36 (36 $\mu$ m thick sample)

TP36. Solid lines in the micrograph indicate high angle boundaries with a misorientation of more than $15 \mathrm{deg}$. Figure 11(b) and 11(c) shows that cube, $\{001\}\langle 100\rangle$ and RD-rotated cube, $\{025\}\langle 100\rangle$ were detected in coarse grains. Therefore, the presence of coarse grains is responsible for the high intensity of cube and RD-rotated cube textures in the deformed state.

Figure 12 shows the grain thickness histogram of TP36. Figure 12(a) shows the measured values from the micrograph of Fig. 11(a); and Fig. 12(b) shows the conversion from the grain thickness of TP450a (annealed $0.45 \mathrm{~mm}$ thick sample), assuming that the thickness changes of grains are homologous with the macroscopic thickness changes. Comparison of two histograms says that grain thickness distribution follows the prediction based on external thickness changes. Inhomogeneous grain size distribution corresponds with that in the initial state. Therefore, the origin of coarse grains with cube and RD-rotated cube orientations in TP36 can be cube- 
(a)

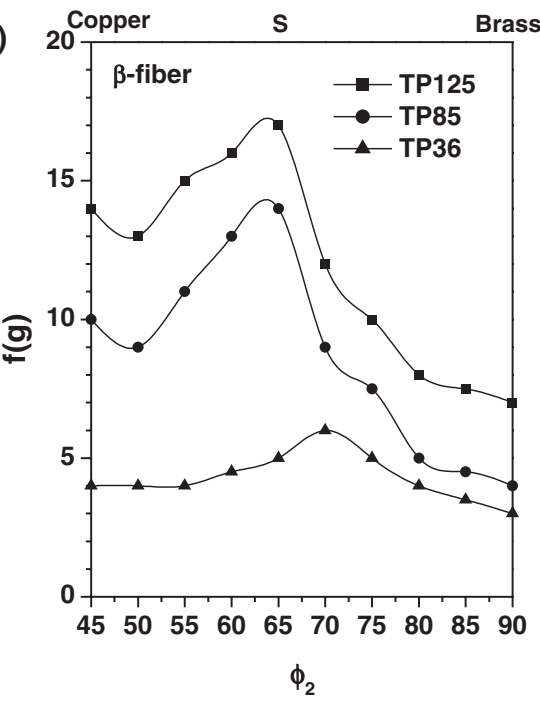

(b)

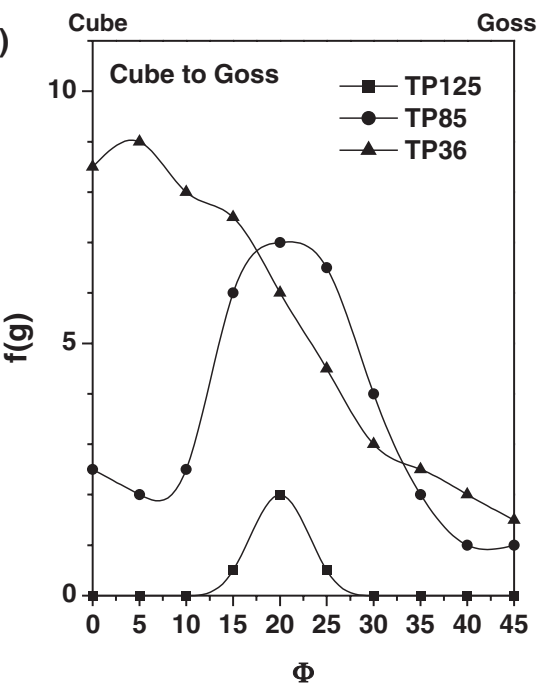

Fig. 8 Orientation densities $\mathrm{f}(\mathrm{g})$ of TP125 (125 $\mu \mathrm{m}$ thick sample), TP85 (85 $\mu \mathrm{m}$ thick sample), and TP36 (36 $\mu \mathrm{m}$ thick sample) (a) along $\beta$-fibers and (b) from $\Phi=0$ to 45 in $\phi_{2}=0$ section.
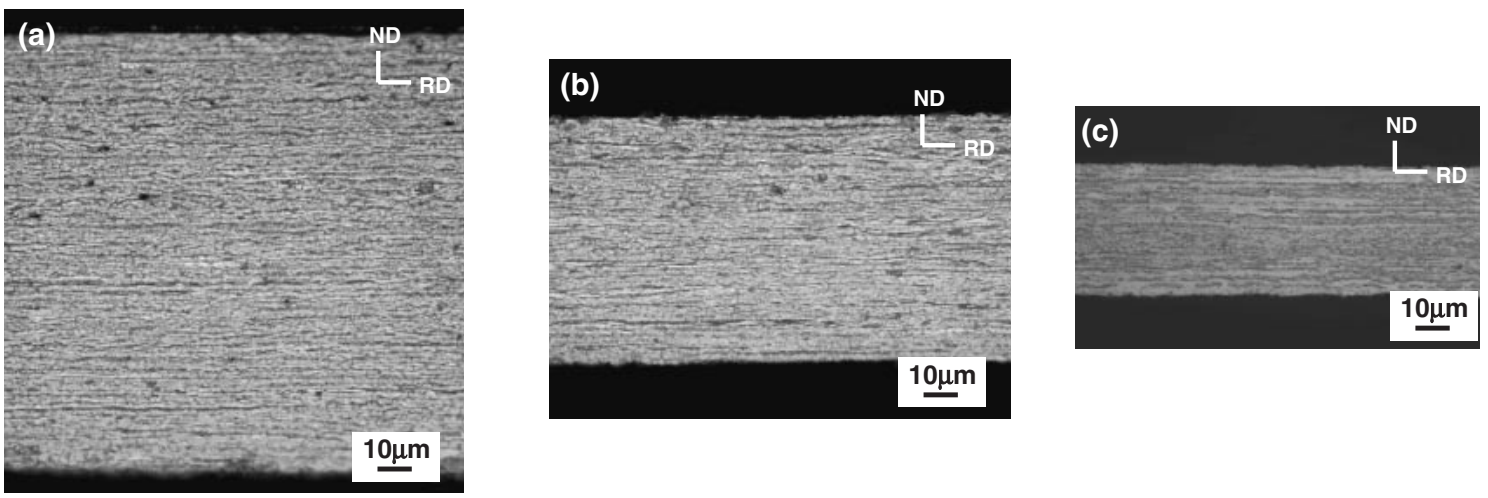

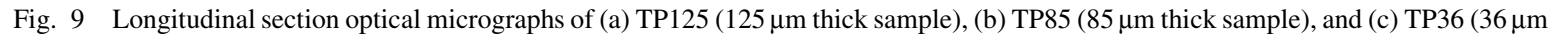
thick sample).
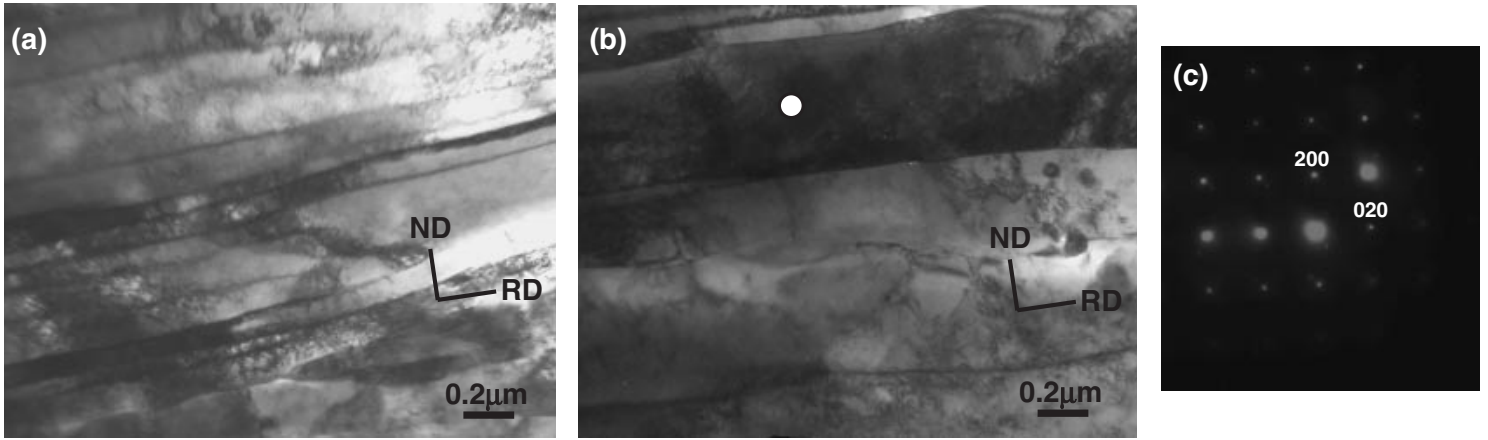

Fig. 10 Longitudinal section TEM micrograph of TP36 (36 $\mu \mathrm{m}$ thick sample) showing (a) refined grains, (b) less refined grains and (c) selected area diffraction pattern at the dotted grain in (b).

oriented coarse grains in TP450a. The cube orientation can reside in rolled state, because this orientation is metastable against deformation. ${ }^{7)}$ Several previous experimental researches showed that deformed cube grains can be present in cold rolled polycrystalline copper. ${ }^{8,9)}$ Researches about single crystallites confirmed the stability of cube orientation and also presented the sequence of orientation changes during rolling. Verbraak reported that cube-oriented single crystalline copper still contains a strong cube texture component even after $99 \%$ cold rolling. ${ }^{10)}$ Other studies on single crystalline copper and aluminum alloy reported that initial cube orientation rotates around the RD (rolling direction) and then changes into $\mathrm{S}$ orientation by additional TD (transverse direction) rotation. ${ }^{11,12)}$ Lattice rotation of crystallite is predicted by the calculation of active slip system under the loading condition. Full constraint Taylor model 

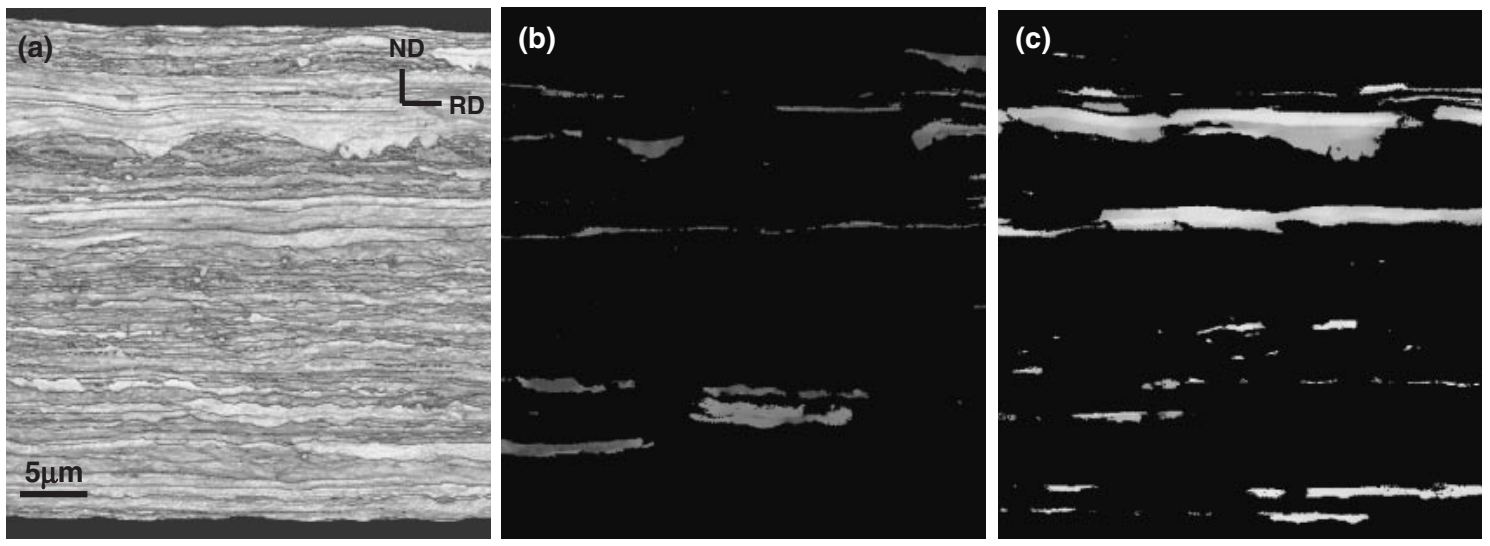

Fig. 11 Longitudinal section EBSD measurement of TP36 (36 $\mu \mathrm{m}$ thick sample) showing (a) pattern quality map, (b) grains of $\{001\}\langle 100\rangle$ orientation with $10 \mathrm{deg}$ tolerance angle, and (c) grains of $\{025\}\langle 100\rangle$ orientation with $10 \mathrm{deg}$ tolerance angle.

(a)

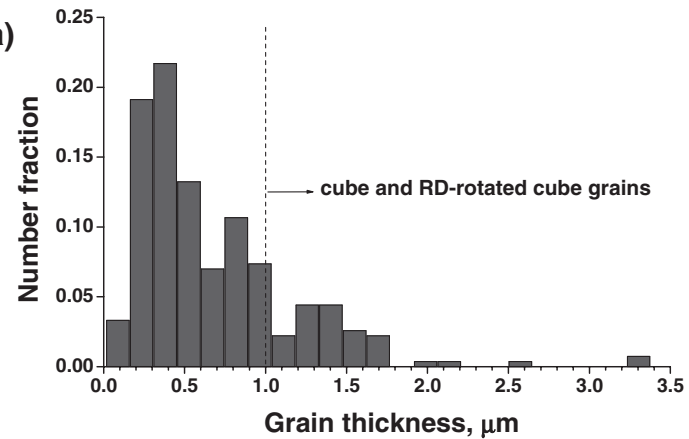

(b)

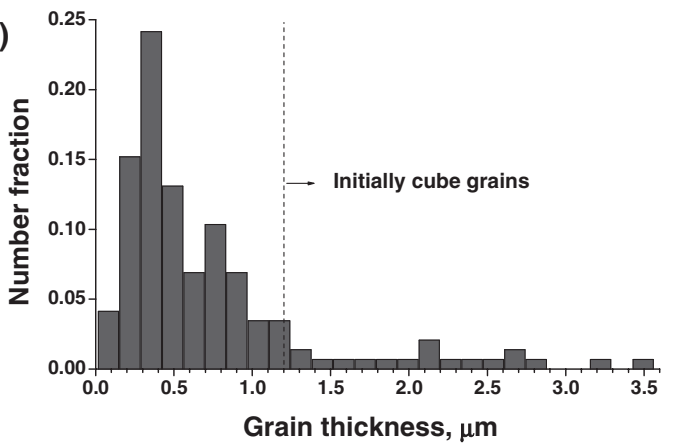

Fig. 12 Grain thickness histogram of (a) TP36 (36 $\mu \mathrm{m}$ thick sample) in Fig. 11 and of (b) conversion from the TP450a (annealed $0.45 \mathrm{~mm}$ thick sample) in Fig. 4 imposed by macroscopic thickness reduction (92\%).

predicts that exact cube orientation is stable and slight deviation from the exact cube orientation is unstable against $\mathrm{RD}$ rotation. TD-rotated cube orientation can be produced by grain subdivision into deformation bands. ${ }^{13)}$ In the present study, no TD-rotated cube orientation was found in both $\mathrm{X}$-ray diffraction and EBSD analysis. Figure 11 shows that cube and RD-rotated cube orientation were present preferentially in the large thickness grains, which should come from large-sized cube-oriented grains before rolling. The orientation of initially cube-oriented coarse grains might be stable against deformation, or changed into RD-rotated cube with increasing deformation. Therefore, the intensity of $\beta$-fiber texture in the rolled state can be directly related to the intensity of cube texture before rolling. Figure 13 shows the orientation densities of the rolling texture components in TP125, TP85, and TP36, as a function of the orientation densities of the cube component in TP1550a, TP1050a, and TP450a. It is clearly seen that the $\beta$-fiber intensity decreases with increasing initial cube texture intensity. Initial texture can influence subsequent rolling texture evolution, but will disappear after a critical reduction if it is unstable against deformation. ${ }^{14,15)}$ The present research reports that the $\beta$-fiber development is very sluggish even after $92 \%$ reduction for the case of an extremely strong initial cube texture and abnormally coarse initial grain structure. Because the initial state before cold rolling was cold rolled to a large reduction in the previous step, it concurrently possessed a

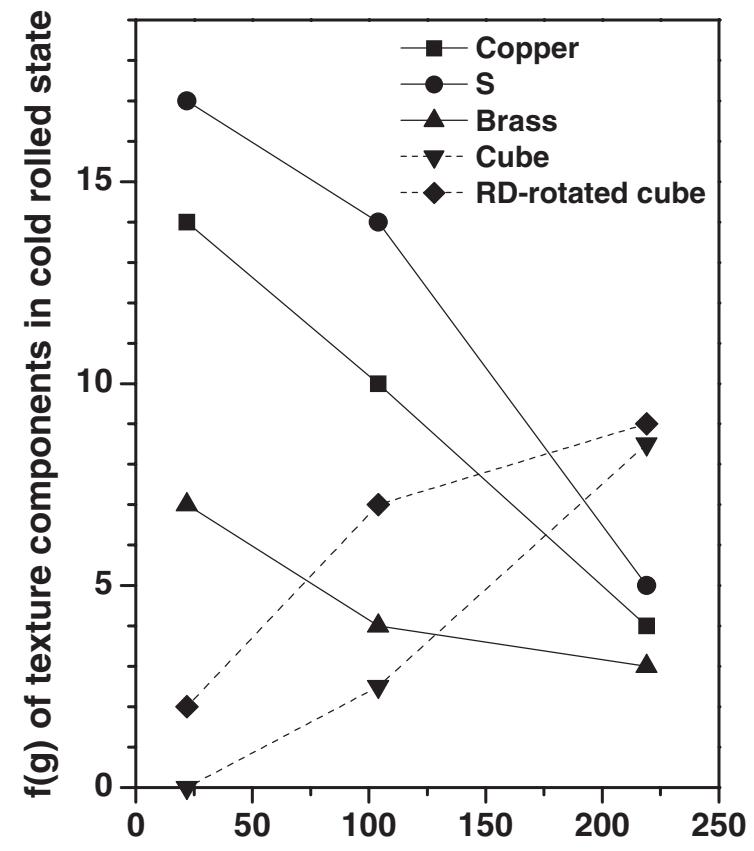

$f(g)$ of cube texture before cold rolling

Fig. 13 Orientation densities of rolling texture components in the cold rolled state as a function of orientation density of cube texture before cold rolling. 
high intensity of cube texture. Unlike bulk-scale products, thin foils inevitably undergo a large amount of rolling reduction from hot rolled strip to final thickness. Therefore, a new strategy of texture control is required in the manufacture of copper foils from a practical point of view.

\section{Conclusion}

Cold rolled copper foils exhibited a high intensity of cube and RD (rolling direction)-rotated cube textures and a low intensity of $\beta$-fiber components. The microstructure before cold rolling was composed of cube-oriented coarse grains and other fine grains. Sluggish development of $\beta$-fiber texture of cold rolled copper foils is mainly attributed to extremely strong initial cube texture.

\section{Acknowledgement}

This work is supported by the Mid-Term Core Technology Development Program of Ministry of Commerce, Industry and Energy in Korea.

\section{REFERENCES}

1) Japan Patent, 11-286760, 1999.

2) T. Hatano, Y. Kurosawa and J. Miyake: J. Electron. Mater. 29 (2000) 611-616.

3) F. J. Humphreys and M. Hatherly: Recrystallization and Related Annealing Phenomena, (Pergamon, Great Britain, 1995) pp. 328-333.

4) G. Simons, K. Kunze, W. Hauffe and J. Dual: Solid State Phenomena 105 (2005) 465-470.

5) S.-H. Kim, S. Z. Han, C. J. Kim, S.-Y. Ok, I.-Y. Hwang and F. Yin: Mater. Sci. Forum 558-559 (2007) 229-234.

6) K. Pawlik: Phys. Status Solidi 134B (1986) 477-483.

7) I. L. Dillamore and H. Katoh: Met. Sci. 8 (1974) 73-83.

8) A. A. Ridha and W. B. Hutchinson: Acta Metall. 30 (1982) 1929-1939.

9) B. J. Duggan, K. Lücke, G. Köhlhoff and C. S. Lee: Acta Metall. Mater. 41 (1993) 1921-1927.

10) C. A. Verbraak: Acta Metall. 6 (1958) 580-597.

11) M. Wróbel, S. Dymek, M. Blicharski and S. Gorczyca: Z. Metallkd. 85 (1994) 415-425.

12) O. Engler, X. W. Kong and K. Lücke: Scr. Mater. 41 (1999) 493-503.

13) F. Basson and J. H. Driver: Acta Mater. 48 (2000) 2101-2115.

14) Z. Chen, X. Zhang, Y. Du, Z. Yao and C. Liu: Mater. Sci. Forum 408412 (2002) 475-480.

15) W. C. Liu, T. Zhai, C.-S. Man, B. Radhakrishnan and J. G. Morris: Phil. Mag. 84 (2004) 3305-3321. 